\title{
Accuracy of non-invasive liver stiffness measurement and steatosis quantification in patients with severe and morbid obesity
}

\author{
Magdalena Eilenberg ${ }^{1,2}$, Petra Munda ${ }^{3}$, Judith Stift ${ }^{4}$, Felix B. Langer ${ }^{1}$, Gerhard Prager ${ }^{1}$, Michael Trauner $^{3}$, \\ Katharina Staufer ${ }^{2,3,5}$
}

${ }^{1}$ Division of General Surgery, Department of Surgery, Medical University of Vienna, Vienna, Austria; ${ }^{2}$ Department of Visceral Surgery and Medicine, Inselspital, University Hospital Bern, Bern, Switzerland; ${ }^{3}$ Division of Gastroenterology \& Hepatology, Department of Internal Medicine III, Medical University of Vienna, Vienna, Austria; ${ }^{4}$ Clinical Institute of Pathology, Medical University of Vienna, Vienna, Austria; ${ }^{5}$ Division of Transplantation, Department of Surgery, Medical University of Vienna, Vienna, Austria

Contributions: (I) Conception and design: M Eilenberg, K Staufer; (II) Administrative support: M Eilenberg, P Munda, J Stift, K Staufer; (III) Provision of study materials or patients: All authors; (IV) Collection and assembly of data: M Eilenberg, P Munda, J Stift, FB Langer, G Prager, K Staufer; (V) Data analysis and interpretation: M Eilenberg, K Staufer; (VI) Manuscript writing: All authors; (VII) Final approval of manuscript: All authors.

Correspondence to: Prof. Dr. Katharina Staufer. Department of Visceral Surgery and Medicine, Inselspital, University Hospital Bern, Freiburgstrasse, 3010 Bern, Switzerland. Email: Katharina.Staufer@insel.ch.

Background: Vibration controlled transient elastography (VCTE) and controlled attenuation parameter $\left(\mathrm{CAP}^{\mathrm{TM}}\right)$ have shown reliable performance predicting fibrosis and steatosis in normal- to overweight patients but have not been validated in severe to morbid obesity. This study aimed at determining the accuracy of VCTE, CAP ${ }^{\mathrm{TM}}$ and the composite score FibroScan-AST (FAST) in patients with a body mass index (BMI) of $\geq 35 \mathrm{~kg} / \mathrm{m}^{2}$.

Methods: Patients scheduled for bariatric-metabolic surgery underwent preoperative VCTE/CAP ${ }^{\mathrm{TM}}$ measurement, and intraoperative liver biopsy. The feasibility and accuracy of VCTE, CAP ${ }^{\mathrm{TM}}$ and the composite score FAST were retrospectively analysed to evaluate fibrosis, steatosis and active fibrotic nonalcoholic steatohepatitis [NASH + non-alcoholic fatty liver disease (NAFLD) activity score $\geq 4+$ fibrosis grade $\geq 2$ ] using per protocol (PP) and intent to diagnose (ITD) calculation.

Results: In total, 170 patients (median BMI $44.4 \mathrm{~kg} / \mathrm{m}^{2}$ ) were included in the study. Liver biopsy showed NASH, simple steatosis, and normal livers in 60.6\% ( $\mathrm{n}=103), 28.8 \%(\mathrm{n}=49)$, and $10.6 \%(\mathrm{n}=18)$, respectively. VCTE and CAP ${ }^{\text {тм }}$ delivered reliable results in $90.6 \%(\mathrm{n}=154 / 170)$ and $90.5 \%(\mathrm{n}=134 / 148)$. The AUC $(\mathrm{PP})$ of VCTE, CAP ${ }^{\mathrm{TM}}$, and FAST were $0.687(\geq \mathrm{F} 2), 0.786(\geq \mathrm{F} 3), 0.703(\geq \mathrm{S} 2), 0.738$ (S3), and 0.780 (active fibrotic NASH). The AUC increased to $0.742(\geq \mathrm{F} 2), 0.842(\geq \mathrm{F} 3), 0.712(\geq \mathrm{S} 2), 0.780(\mathrm{~S} 3)$, and 0.836 (active fibrotic NASH) in patients below the median BMI of $44.4 \mathrm{~kg} / \mathrm{m}^{2}$.

Conclusions: VCTE, CAP ${ }^{\mathrm{TM}}$ and FAST show acceptable accuracy for the detection of fibrosis, steatosis and NASH in a real-life cohort of patients with obesity. Accuracy improves in patients with a BMI $<44.4 \mathrm{~kg} / \mathrm{m}^{2}$.

Keywords: Transient elastography; controlled attenuation parameter (CAP $\left.{ }^{\mathrm{TM}}\right)$; FibroScan-AST score (FAST score); obesity; non-alcoholic fatty liver disease (NAFLD)

Submitted Nov 04, 2020. Accepted for publication Dec 24, 2020.

doi: $10.21037 / \mathrm{hbsn}-20-787$

View this article at: https://dx.doi.org/10.21037/hbsn-20-787 


\section{Introduction}

Obesity and the concomitant metabolic syndrome are associated with a high risk of non-alcoholic fatty liver disease (NAFLD). Up to $90 \%$ of patients with obesity are affected by NAFLD (1). In about half of the patients with NAFLD and obesity with a body mass index (BMI) $\geq 35 \mathrm{~kg} / \mathrm{m}^{2}$ non-alcoholic steatohepatitis (NASH) is present (2), and up to $5 \%$ of patients who undergo bariatricmetabolic surgery suffer from undiagnosed cirrhosis at the time of surgery (3). As obesity becomes an increasing burden, NAFLD has become the most common chronic liver disease worldwide, and is predicted to become the most frequent cause for liver transplantation in the Western World (4).

Bariatric-metabolic surgery has been shown to reduce obesity-related comorbidities in patients with severe (BMI $\geq 35-39.9 \mathrm{~kg} / \mathrm{m}^{2}$ ) and morbid obesity (BMI $\geq 40 \mathrm{~kg} / \mathrm{m}^{2}$ ) including liver steatosis and fibrosis in the majority of patients (5). Thus, NAFLD/NASH itself is increasingly discussed as an explicit indication for bariatricmetabolic surgery (6), and was shown to be cost-effective for patients with obesity and NASH regardless of fibrosis stage, as well as in patients with overweight and advanced fibrosis $(\geq \mathrm{F} 3)$ (7). Bariatric-metabolic surgery has also been performed in compensated and decompensated cirrhosis. However, in these patient cohorts, the perioperative mortality was increased to $0.9 \%$, and $16.3 \%$, respectively, in comparison to patients without cirrhosis $(0.3 \%)$ (8). Data is still inconclusive upon the choice of the optimal bariatric-metabolic surgical technique in patients with advanced fibrosis or cirrhosis, and preoperative assessment of liver alterations is essential to avoid unnecessary risks for the patient.

In order to optimally select candidates for bariatricmetabolic surgery non-invasive tools are required, which also allow to assess currently applied endpoints in clinical trials for the treatment of NAFLD/NASH, i.e., resolution of NASH without worsening of fibrosis, or reduction of fibrosis without worsening of NASH.

Vibration controlled transient elastography (VCTE; FibroScan ${ }^{\circledR}$ Echosens, Paris, France) has shown promising results as a non-invasive screening tool for significant and advanced liver fibrosis by liver stiffness measurement (LSM; $\mathrm{kPa}$ ) in normal to overweight patients with various liver diseases $(9,10)$. Furthermore, controlled attenuation parameter $\left(\mathrm{CAP}^{\mathrm{TM}}\right)$, which was developed to quantify ultrasound attenuation during LSM by VCTE (FibroScan ${ }^{\circledR}$ $\mathrm{CAP}^{\mathrm{TM}}$ ) has been used to non-invasively quantify liver steatosis in lean patients. A recent individual patient data based meta-analysis on CAP ${ }^{\mathrm{TM}}$ in 2,735 patients with mainly viral hepatitis and NAFLD/NASH and a mean BMI of $25.0 \mathrm{~kg} / \mathrm{m}^{2}$ reported good accuracy for the detection of significant $(\geq \mathrm{S} 2$, AUC 0.865$)$ and severe (S3, AUC 0.882) steatosis (11).

With regard to non-invasive diagnosis of NASH by LSM/CAP ${ }^{\mathrm{TM}}$, a recent prospective UK multicentre study reported only poor to fair accuracy (LSM: AUC 0.68, CAP $^{\mathrm{TM}}$ : AUC 0.71 ) in a patient cohort with a median BMI of $33.8 \mathrm{~kg} / \mathrm{m}^{2}$ (12). Of note, LSM by FibroScan ${ }^{\circledR}$ and $\mathrm{CAP}^{\mathrm{TM}}$ have considerable limitations in patients with a $\mathrm{BMI} \geq 30 \mathrm{~kg} / \mathrm{m}^{2}(9,13,14)$. An increased subcutaneous fat proportion or waist circumference were identified as independent predictors of measurement failure using the M-probe $(15,16)$, which lead to the development of the XL probe to improve reliability of LSM in patients with overweight and obesity $(17,18)$. Recently, a new composite score for NAFLD consisting of LSM by VCTE, CAP'M and aspartate aminotransferase (AST), the so-called FAST score, was evaluated and tested on the outcome parameter of active fibrotic NASH (NASH $+\mathrm{NAS} \geq 4+\mathrm{F} \geq 2$ ). In the study by Newsome et al. FAST identified patients with an AUC of 0.80 (median BMI $34.2 \mathrm{~kg} / \mathrm{m}^{2}$ ), who were at the highest risk of disease progression and had an excellent AUC of 0.95 for active fibrotic NASH in patients with severe and morbid obesity (median BMI $43.0 \mathrm{~kg} / \mathrm{m}^{2}$ ) (19).

Therefore, the aim of this study was to evaluate the accuracy of LSM, CAP ${ }^{\mathrm{TM}}$ and FAST score for noninvasive detection of significant and advanced liver fibrosis, significant and severe steatosis, and diagnosis of NASH in a patient cohort with severe and morbid obesity undergoing bariatric-metabolic surgery, in a real life setting.

\section{Methods}

The study was performed in consecutive patients with severe and morbid obesity scheduled for bariatric-metabolic surgery from September 2014 through November 2018. Surgery was performed in the presence of BMI $\geq 35 \mathrm{~kg} / \mathrm{m}^{2}$ in combination with one or more obesity-related comorbidities (i.e., metabolic disorders, cardiorespiratory disease, severe joint disease), or in the presence of a BMI $\geq 40 \mathrm{~kg} / \mathrm{m}^{2}$ according to the European Guidelines on Metabolic and Bariatric Surgery (20). Roux-en-Y gastric bypass, one-anastomosis gastric bypass, sleeve gastrectomy and other bariatric-metabolic procedures were performed in $55(32.4 \%), 94(55.3 \%), 15(8.8 \%)$ and $6(3.5 \%)$ patients. 
Feasibility and accuracy of LSM, steatosis quantification and detection of NASH was assessed by VCTE, CAP ${ }^{\mathrm{TM}}$, and FAST score prior to surgery using intraoperative liver biopsy as a reference standard.

Laboratory parameters reflecting relevant components of the metabolic syndrome [i.e., total cholesterol, triglycerides, high-density lipoprotein (HDL); low-density lipoprotein (LDL), glycosylated haemoglobin A1 (HbA1c), homeostatic model assessment for insulin resistance (HOMA-IR)] and liver alteration [AST, alanine aminotransferase (ALT), gamma-glutamyl transferase (GGT), platelets, ferritin, albumin] were assessed within 14 days prior to surgery and three and 12 months after surgery.

Comorbidities as signs of the metabolic syndrome were documented according to the International Diabetes Federation consensus on the metabolic syndrome (21), including HOMAIR as a measure of impaired glucose tolerance (22).

Patients with liver disease other than NAFLD were excluded by assessing daily ethanol consumption $(<20 \mathrm{~g}$ ethanol in females, $<30 \mathrm{~g}$ ethanol in males) and standard laboratory testing.

The authors are accountable for all aspects of the work in ensuring that questions related to the accuracy or integrity of any part of the work are appropriately investigated and resolved. The study was conducted in accordance with the Declaration of Helsinki (as revised in 2013). The study was approved by institutional ethics board of the Medical University of Vienna (vote number 2297/2017) and individual consent for this retrospective analysis was waived. We present the following article in accordance with the Liver-FibroSTARD reporting checklist for data (23) and completed the STARD reporting checklist as required (available at https://hbsn.amegroups.com/article/ view/10.21037/hbsn-20-787/rc).

\section{VCTE}

VCTE was performed according to manufacturer's recommendations (FibroScan ${ }^{\circledR}$, Echosens, Paris, France) by independent, experienced examiners in fasted patients using the XL probe prior to surgery at the out-patient service of a tertiary university medical centre. Patients with VCTE examinations performed $>6$ months prior to surgery were excluded from analysis. At least 10 valid measurements were performed. LSM values $(\mathrm{kPa})$ were considered unreliable if IQR/median was $>30 \%$ for values above $7.0 \mathrm{kPa}(23)$. CAP ${ }^{\mathrm{TM}}(\mathrm{dB} / \mathrm{m})$, calculated simultaneously with LSM measurements, was used as a quantitative indicator of hepatic steatosis using the median of 10 valid measurements. FAST score

In line with the publication on FibroScan-AST (FAST) score for NASH detection by Newsome et al., FAST was calculated using the equation below and tested on the outcome parameters significant fibrosis $(\geq \mathrm{F} 2)$, significant steatosis $(\geq \mathrm{S} 2)$, NASH according to SAF and active fibrotic NASH (19).

$$
\begin{aligned}
& \text { FAST } \\
& =\frac{\mathrm{e}\left(-1.65+1.07 \times \ln (\mathrm{LSM})+2.66 * 10^{-8} \times \mathrm{CAP}^{3}-63.3 \times \mathrm{AST}^{-1}\right)}{1+\mathrm{e}\left(-1.65+1.07 \times \ln (\mathrm{LSM})+2.66 * 10^{-8} \times \mathrm{CAP}^{3}-63.3 \times \mathrm{AST}^{-1}\right)}
\end{aligned}
$$

\section{Liver biopsy}

Liver biopsy was routinely performed intraoperatively during bariatric-metabolic surgery on the left liver lobe under direct visualization using a 14-gauge $17-\mathrm{cm}$ Trucut $^{\mathrm{TM}}$ needle (ACHIEVE programmable automatic biopsy system CareFusion Waukegan, IL, USA). Biopsy specimens were at least $1.5 \mathrm{~cm}$ long and displayed $\geq 6$ portal fields. Histological specimens were analysed and graded with regard to steatosis, hepatocyte ballooning, lobular inflammation and fibrosis by two independent experienced pathologists according to NAFLD Activity Score (NAS) and Steatosis, Activity and Fibrosis (SAF) Score $(24,25)$. Briefly, steatosis grades were divided by percentage of macrovesicular steatosis in S1 (5-33\% of hepatocytes), S2 (34-66\% of hepatocytes) and S3 (>66\% of hepatocytes). Fibrosis was grouped accordingly in F0-F1 (no fibrosis or portal fibrosis without septa), F2 (portal fibrosis with few septa), F3 (numerous septa without cirrhosis) and F4 (cirrhosis).

\section{Statistics}

Patient characteristics and clinical data were descriptively reported as medians [quartile $1(\mathrm{Q} 1)$; quartile $3(\mathrm{Q} 3)$ ] and frequencies (\%). Group comparisons were performed by Chi-Square or Fisher's exact tests for categorical variables as appropriate, and ANOVA and student's $t$-test (after checking for normal distribution by Levene test) or MannWhitney U-test (for non-normal distributed variables) for parametric and non-parametric continuous variables. The diagnostic accuracy of VCTE and CAP ${ }^{\mathrm{TM}}$ as compared to liver histology was determined using areas under the receiver operating characteristics (AUC) at a confidence 


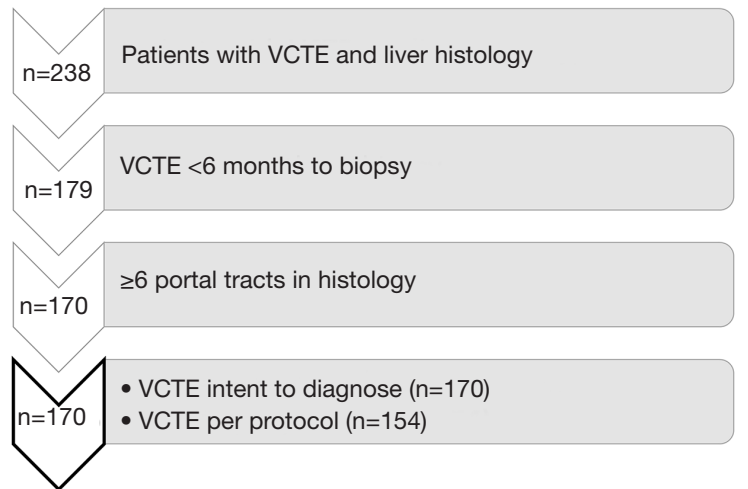

Figure 1 Flow chart of study population. Patients with VCTE examinations $>6$ months prior to surgery, as well as $<6$ portal tracts in histology were excluded from analysis. VCTE, vibration controlled transient elastography.

interval of $95 \%$ (95\% CI). We performed a per protocol (PP) analysis excluding unreliable results as well as an intentto-diagnose (ITD) analysis based on all VCTE, CAP ${ }^{\mathrm{TM}}$ and FAST examinations including failed measurements. The diagnostic accuracy for significant fibrosis $(\geq \mathrm{F} 2)$ and advanced fibrosis $(\geq F 3)$, significant steatosis $(\geq \mathrm{S} 2)$ and advanced steatosis (S3) and NASH according to SAF were examined, and sensitivity and specificity were calculated. The optimal cut offs were analysed according to Youden Index (26). LSM/CAP ${ }^{\mathrm{TM}}$ results (PP and ITD) were further stratified according to BMI. In a subgroup analysis we aimed to evaluate the influencing factors of steatosis and BMI on VCTE by assessing its accuracy in patients with steatosis $<\mathrm{S} 3$ and/or $<$ median BMI of the study cohort.

Factors influencing LSM and CAP values were identified using uni- and multivariate linear regression analysis. Available laboratory parameters, patients' age and BMI were tested by univariate linear regression. Values with a significance level $<0.02$ were further analysed by multivariate linear regression using the enter method.

All statistical analyses were performed using SPSS Version 23 (SPSS Inc., Chicago, IL, USA). The significance level was set at $\mathrm{P}<0.05$.

\section{Results}

\section{Study population}

In total, in 238 patients VCTE was performed prior to bariatric-metabolic surgery. Study patients were excluded either if LSM was performed $>6$ months prior to surgery $(\mathrm{n}=59)$, or evaluability of liver biopsy was limited ( $<6$ portal fields present, n=9) (Figure 1). Consequently, 170 patients ( $64.7 \%$ female, median age 42.0 years) were included in the final analysis. Patients with missing data were excluded from analysis and the number of patients is stated accordingly. The median BMI at the time of VCTE was $44.4 \mathrm{~kg} / \mathrm{m}^{2}$ (Q1; Q3: 41.3; 48.8). Although patients were asked to lose 5 to $10 \mathrm{~kg}$ prior to surgery, the majority did not succeed, so that the median BMI at surgery was similar to that at the time of VCTE (44.2 kg/m², Q1; Q3: 41.0; 48.4, $\mathrm{P}=0.911)$. Patients with a BMI $\geq$ or $<$ the median BMI of $44.4 \mathrm{~kg} / \mathrm{m}^{2}$ at VCTE did not differ in terms of comorbidities (T2DM $\mathrm{P}=0.449$, aHTN $\mathrm{P}=0.376$, hypertriglyceridemia $\mathrm{P}=0.387$, hypercholesterolaemia $\mathrm{P}=0.277$, hyperuricaemia $\mathrm{P}=0.165$ ). Patients' characteristics are demonstrated in Table 1.

\section{Liver histology}

In total, $152(89.4 \%)$ patients had features of NAFLD, 49 (28.8\%) patients were classified as NAFL, $103(60.6 \%)$ patients were classified as NASH. Significant to advanced fibrosis $(\geq \mathrm{F} 2)$ was present in $37(21.8 \%)$ patients, advanced fibrosis $(\geq \mathrm{F} 3)$ was present in $14(8.2 \%)$ patients, significant to severe steatosis was present in $72(42.4 \%)$ patients, severe steatosis was present in 39 (22.9\%) patients. The results of liver biopsy are presented in Table 2.

\section{Feasibility and accuracy of LSM and CAP ${ }^{\mathrm{TM}}$}

Data on diagnostic accuracy for LSM by VCTE (ITD and $\mathrm{PP}$ ) as well as diagnostic accuracy of quantitative steatosis measurement by CAP ${ }^{\mathrm{TM}}$ (ITD and PP) are presented in Figure 2. The results of LSM and CAP ${ }^{\mathrm{TM}}$ measurement stratified according to liver histology are displayed in Figure 3 and Table S1.

VCTE/CAP ${ }^{\mathrm{TM}}$ results were stratified according to the median BMI of $44.4 \mathrm{~kg} / \mathrm{m}^{2}$. The median time interval between VCTE/CAP ${ }^{\mathrm{TM}}$ and liver biopsy was 2.9 months (Q1; Q3: 1.6; 4.6).

ITD analysis, taking all LSM measurements into account $(\mathrm{n}=170)$, showed an AUC for $\geq \mathrm{F} 2$ and $\geq \mathrm{F} 3$ of 0.670 , and 0.758. Stratified according to BMI, in patients with a BMI $<44.4 \mathrm{~kg} / \mathrm{m}^{2}(\mathrm{n}=84)$ an AUC for $\geq \mathrm{F} 2$ and $\geq \mathrm{F} 3$ of 0.727 , and 0.831 was reached, respectively. In patients with a BMI $\geq 44.4 \mathrm{~kg} / \mathrm{m}^{2}(\mathrm{n}=85)$ the AUC for $\geq \mathrm{F} 2$ and $\geq \mathrm{F} 3$ was 0.614 , and 0.677 .

PP analysis, including only valid VCTE measurements $(\mathrm{n}=154)$, showed an AUC for $\geq \mathrm{F} 2$ and $\geq \mathrm{F} 3$ of 0.687 and 


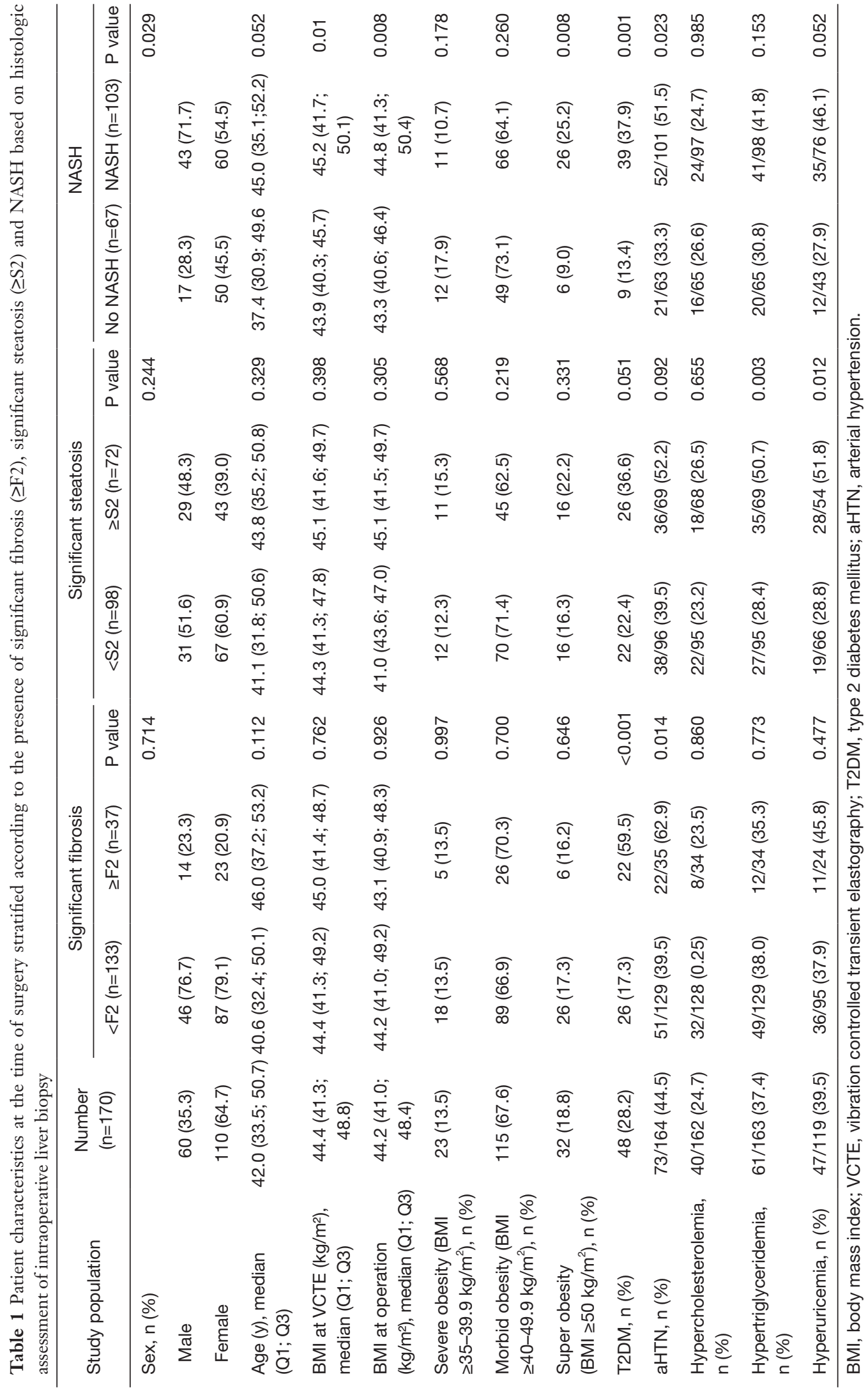


Table 2 Liver histology of intraoperative liver biopsy

\begin{tabular}{|c|c|}
\hline Histologic findings & Number $(n=170)$ \\
\hline \multicolumn{2}{|l|}{ Fibrosis stage, n (\%) } \\
\hline F0-1 & $133(78.2)$ \\
\hline $\mathrm{F} 2$ & $23(13.5)$ \\
\hline F3 & $12(7.1)$ \\
\hline $\mathrm{F} 4$ & $2(1.2)$ \\
\hline \multicolumn{2}{|l|}{ Steatosis grade, n (\%) } \\
\hline so & $18(10.6)$ \\
\hline S1 & $80(47.1)$ \\
\hline S2 & $33(19.4)$ \\
\hline S3 & $39(22.9)$ \\
\hline \multicolumn{2}{|l|}{ NAS, n (\%) } \\
\hline NAS 0-2 & $56(32.9)$ \\
\hline NAS 3-4 & $67(39.4)$ \\
\hline NAS $\geq 5$ & $47(27.7)$ \\
\hline NAS, median (Q1; Q3) & $3(2 ; 5)$ \\
\hline \multicolumn{2}{|l|}{ SAF, n (\%) } \\
\hline No steatosis & $18(10.6)$ \\
\hline NAFL & $49(28.8)$ \\
\hline $\mathrm{NASH}$ & $103(60.6)$ \\
\hline
\end{tabular}

NAFLD was classified according to NAS and SAF. In liver biopsies, a median of 12 (Q1; Q3: 8; 15.8) portal tracts were present. NAS, NAFLD Activity Score; SAF, Steatosis Activity and Fibrosis score; NAFLD; non-alcoholic fatty liver disease; NASH, non-alcoholic steatohepatitis; F, fibrosis grade; $\mathrm{S}$, steatosis grade.

0.786, respectively. Stratified according to BMI, in patients with a $\mathrm{BMI}<44.4 \mathrm{~kg} / \mathrm{m}^{2}(\mathrm{n}=82)$ an AUC for $\geq \mathrm{F} 2$ and $\geq \mathrm{F} 3$ of 0.742 , and 0.842 was achieved. In patients with a BMI $\geq 44.4 \mathrm{~kg} / \mathrm{m}^{2}(\mathrm{n}=72)$ the AUC for $\geq \mathrm{F} 2$ and $\geq \mathrm{F} 3$ was 0.616 , and 0.702 , respectively. The cut off for $\geq \mathrm{F} 2$ was $6.3 \mathrm{kPa}$ with a sensitivity of $78.8 \%$ and specificity of $53.7 \%$. The cut off for $\geq \mathrm{F} 3$ was $12.6 \mathrm{kPa}$ with a sensitivity and specificity of $53.8 \%$ and $91.5 \%$, respectively.

$\mathrm{CAP}^{\mathrm{TM}}$ showed an AUC (ITD/PP) for $\geq \mathrm{S} 2$ and $\mathrm{S} 3$ of $0.690 / 0.703$, and $0.725 / 0.738$, respectively. Stratifying according to the median BMI of $<44.4 \mathrm{~kg} / \mathrm{m}^{2}$, CAP ${ }^{\mathrm{TM}}$ achieved an AUC (ITD/PP) for $\geq \mathrm{S} 2$ and $\mathrm{S} 3$ of $0.706 / 0.712$, and $0.783 / 0.780$. The cut off (PP) for $\geq \mathrm{S} 2$ was $350.0 \mathrm{~dB} / \mathrm{m}$ and for $\mathrm{S} 3$ it was $353.5 \mathrm{~dB} / \mathrm{m}$, respectively.
As LSM values were significantly higher in advanced steatosis and NASH (NAS and SAF, see Table S1) we aimed to assess the influence of S3 on the accuracy of VCTE. Therefore, we performed a subgroup analysis of patients with $<\mathrm{S} 3$. In patients with $<\mathrm{S} 3$ the AUC (ITD/ $\mathrm{PP}$ ) for $\geq \mathrm{F} 2$ and $\geq \mathrm{F} 3$ was $0.673 / 0.699$, and $0.747 / 0.801$. In a further subgroup analysis, patients with $<\mathrm{S} 3$ and a BMI of $<44.4 \mathrm{~kg} / \mathrm{m}^{2}$ had an improved AUC for $\geq \mathrm{F} 2(0.702 / 0.721)$ and $\geq \mathrm{F} 3(0.842 / 0.856)$ compared to patients with a BMI $\geq 44.4 \mathrm{~kg} / \mathrm{m}^{2}(\geq \mathrm{F} 2: 0.647 / 0.668, \geq \mathrm{F} 3$ 0.621/0.706).

In total, $16(9.4 \%)$ VCTE/CAP ${ }^{\mathrm{TM}}$ measurements delivered unreliable results. The patients concerned had a significantly higher median BMI $\left[50.1 \mathrm{~kg} / \mathrm{m}^{2}(\mathrm{Q} 1 ; \mathrm{Q} 3\right.$ : 45.3; 56.4) vs. $44.2 \mathrm{~kg} / \mathrm{m}^{2}$ (Q1; Q3: 41.2;47.8), $\left.\mathrm{P}<0.001\right]$. In addition, the rate of unreliable results was higher in patients with a $\mathrm{BMI}$ of $\geq 44.4 \mathrm{~kg} / \mathrm{m}^{2}(16.3 \%$ vs. $2.4 \%, \mathrm{P}=0.002)$. However, severity of steatosis $(\mathrm{P}=0.654)$ and fibrosis $(\mathrm{P}=0.932)$ according to histology did not differ between patients with valid and invalid measurements. Median LSM and $\mathrm{CAP}^{\mathrm{TM}}$ values of invalid measurements were significantly higher [LSM $19.4 \mathrm{kPa}(\mathrm{Q} 1 ; \mathrm{Q} 3: 12.2 ; 26.4) v s$. $6.5 \mathrm{kPa}$ (Q1; Q3: 5.0; 9.43), $\mathrm{P}<0.0001$, CAP ${ }^{\mathrm{TM}} 385 \mathrm{~dB} / \mathrm{m}$ (Q1; Q3: 325.5; 400) vs. 336 dB/m (Q1; Q3: 305.8; 375), $\mathrm{P}=0.036]$.

\section{Non-invasive diagnosis of $\mathrm{NASH}$}

The diagnostic accuracy of VCTE for the detection of $\mathrm{NASH}$ according to SAF was assessed. VCTE detected NASH with an AUC (ITD/PP) of 0.628/0.640. In patients with a BMI $<44.4 \mathrm{~kg} / \mathrm{m}^{2}$ AUC (ITD/PP) was $0.540 / 0.547$ and was increased in patients with $\geq 44.4 \mathrm{~kg} / \mathrm{m}^{2}$ (AUC 0.696/0.745).

$\mathrm{CAP}^{\mathrm{TM}}$ predicted NASH with an AUC (ITD/PP) of $0.758 / 0.758$. In patients with a BMI $<44.4 \mathrm{~kg} / \mathrm{m}^{2}$ AUC (ITD/PP) improved (0.786/0.793).

FAST score was available in 147 (ITD; $\mathrm{n}=133 \mathrm{PP}$ ) patients. In total, 23 patients (17.3\%) were found at risk of progressive NASH (active fibrotic NASH). The AUC (ITD/ $\mathrm{PP}$ ) for $\geq \mathrm{F} 2$ and $\geq \mathrm{F} 3$ was $0.668 / 0.666$ and $0.628 / 0.729$, respectively. For the detection of $\geq \mathrm{S} 2$ and $\mathrm{S} 3$ the AUC was $0.817 / 0.838$ and $0.786 / 0.812$, respectively. For NASH according to SAF and active fibrotic NASH the AUC was $0.784 / 0.781$, and $0.764 / 0.780$. Stratification for BMI $<44.4$ $\mathrm{kg} / \mathrm{m}^{2}$ improved the AUC (ITD/PP) for the diagnosis of active fibrotic NASH $(0.828 / 0.836)$ but had no effect on NASH according to SAF for PP analysis (AUC 0.788/0.787). 


\begin{tabular}{|c|c|c|c|c|c|c|c|c|c|c|c|c|c|c|c|c|c|c|c|c|c|}
\hline VCTE (PP) (Fibrosis) & $A U C \geq F 2$ & Cut off $(\mathrm{kPa})$ & Youden Index & Sens. & Spec. & $A U C \geq F 3$ & Cut off (kPA) & Youden Index & Sens. & Spec. & VCTE (ITD) (Fibrosis) & $\mathrm{AUC} \geq \mathrm{F} 2$ & Cut off (kPA) & Youden Index & Sens. & Spec. & $A \cup C \geq F 3$ & Cut off (kPA) & Youden Index & Sens. & Spec. \\
\hline All patients (n=154) & 0.687 & 6.3 & 0.325 & 78.8 & 53.7 & 0.786 & 12.6 & 0.453 & 53.8 & 91.5 & All patients $(n=170)$ & 0.670 & 6.3 & 0.294 & 80.6 & 48.9 & 0.758 & 12.6 & 0.436 & 57.1 & 86.5 \\
\hline BMI $<44.4 \mathrm{~kg} / \mathrm{m}^{2}(\mathrm{n}=82)$ & 0.742 & 8.3 & 0.424 & 61.1 & 81.3 & 0.842 & 8.4 & 0.630 & 85.7 & 77.3 & $\mathrm{BMI}<44.4 \mathrm{~kg} / \mathrm{m}^{2}(\mathrm{n}=84)$ & 0.727 & 8.4 & 0.399 & 61.1 & 78.8 & 0.831 & 8.4 & 0.610 & 85.7 & 75.3 \\
\hline $\mathrm{BMI} \geq 44.4 \mathrm{~kg} / \mathrm{m}^{2}(\mathrm{n}=72)$ & 0.616 & 6.3 & 0.288 & 86.7 & 42.1 & 0.702 & 14.1 & 0.394 & 50.0 & 89.4 & $\mathrm{BMI} \geq 44.4 \mathrm{~kg} / \mathrm{m}^{2}(\mathrm{n}=85)$ & 0.614 & 6.3 & 0.247 & 88.9 & 358.0 & 0.677 & 14.1 & 0.392 & 57.1 & 82.1 \\
\hline$<S 3(n=117)$ & 0.699 & 6.3 & 0.345 & 76.2 & 58.3 & 0.801 & 8.4 & 0.513 & 70.0 & 81.3 & $<S 3(n=131)$ & 0.673 & 6.3 & 0.306 & 78.3 & 52.3 & 0.747 & 8.4 & 0.433 & 70.0 & 73.3 \\
\hline$<S 3, \mathrm{BMI}<44.4 \mathrm{~kg} / \mathrm{m}^{2}(\mathrm{n}=65)$ & 0.721 & 9.7 & 0.360 & 41.7 & 94.3 & 0.856 & 8.4 & 0.681 & 83.3 & 84.7 & $<S 3, \mathrm{BMI}<44.4 \mathrm{~kg} / \mathrm{m}^{2}(\mathrm{n}=67)$ & 0.702 & 9.7 & 0.326 & 41.7 & 90.9 & 0.842 & 8.4 & 0.653 & 83.3 & 82.0 \\
\hline CAPTM (PP) (Steatosis) & $A \cup C \geq S 2$ & Cut off $(\mathrm{dB} / \mathrm{m})$ & Youden Index & Sens. & Spec. & AUC S3 & Cut off (dB/m) & Youden Index & Sens. & Spec. & CAP'M (ITD) (Steatosis) & $\mathrm{AUC} \geq \mathrm{S} 2$ & Cut off $(\mathrm{dB} / \mathrm{m})$ & Youden Index & Sens. & Spec. & AUC s3 & Cut off $(\mathrm{dB} / \mathrm{m})$ & Youden Index & Sens. & Spec. \\
\hline All patients $(n=134)$ & 0.703 & 350.0 & 0.367 & 63.0 & 73.8 & 0.738 & 353.5 & 0.466 & 75.0 & 71.6 & All patients $(n=148)$ & 0.690 & 350 & 0.338 & 63.3 & 70.5 & 0.725 & 353.5 & 0.449 & 76.5 & 68.4 \\
\hline BMI $<44.4 \mathrm{~kg} / \mathrm{m}^{2}(\mathrm{n}=68)$ & 0.712 & 311.5 & 0.398 & 84.0 & 55.8 & 0.780 & 325.5 & 0.574 & 100.0 & 57.4 & BMI $<44.4 \mathrm{~kg} / \mathrm{m}^{2}(\mathrm{n}=70)$ & 0.706 & 311.5 & 0.392 & 84.6 & 54.5 & 0.783 & 325.5 & 0.554 & 100.0 & 55.4 \\
\hline BMI $\geq 44.4 \mathrm{~kg} / \mathrm{m}^{2}(\mathrm{n}=68)$ & 0.687 & 333.5 & 0.407 & 75.9 & 64.9 & 0.701 & 369.5 & 0.472 & 72.2 & 75.0 & BMI $\geq 44.4 \mathrm{~kg} / \mathrm{m}^{2}(\mathrm{n}=78)$ & 0.666 & 371.5 & 0.368 & 61.8 & 75.0 & 0.680 & 371.5 & 0.457 & 75.0 & 70.7 \\
\hline FAST (PP) (Fibrosis) & $A U C \geq F 2$ & Cut off $(\mathrm{kPa})$ & Youden Index & Sens. & Spec. & $A U C \geq F 3$ & Cut off $(k P A)$ & Youden Index & Sens. & Spec. & FAST (TDD) (Fibrosis) & $\mathrm{AUC} \geq \mathrm{F} 2$ & Cut off (kPA) & Youden Index & Sens. & Spec. & $A \cup C \geq F 3$ & Cut off (kPA) & Youden Index & Sens. & Spec. \\
\hline All patients (n=133) & 0.666 & 0.301 & 0.453 & 73.1 & 57.0 & 0.729 & 0.714 & 0.380 & 44.4 & 93.5 & All patients $(n=147)$ & 0.668 & 0.642 & 0.295 & 41.4 & 88.1 & 0.728 & 0.714 & 0.405 & 50.0 & 90.5 \\
\hline FAST (PP) (Steatosis) & $A \cup C \geq S 2$ & Cut off ( $(\mathrm{dB} / \mathrm{m})$ & Youden Index & Sens. & Spec. & AUC S3 & Cut off $(\mathrm{dB} / \mathrm{m})$ & Youden Index & Sens. & Spec. & FAST (ITD) (Steatosis) & $\mathrm{AUC} \geq \mathrm{S} 2$ & Cut off $(\mathrm{dB} / \mathrm{m})$ & Youden Index & Sens. & Spec. & AUC s3 & Cut off $(\mathrm{dB} / \mathrm{m})$ & Youden Index & Sens. & Spec. \\
\hline All patients $(n=133)$ & 0.838 & 0.261 & 0.611 & 85.5 & 75.6 & 0.812 & 0.303 & 0.568 & 87.5 & 69.3 & All patients $(n=147)$ & 0.817 & 0.261 & 0.578 & 86.9 & 57.8 & 0.786 & 0.303 & 0.538 & 88.6 & 65.2 \\
\hline VCTE (PP) (NASH) & AUC & Cut off $(\mathrm{kPa})$ & Youden Index & Sens. & Spec. & & & & & & VCTE (ITD) (NASH) & AUC & Cut off (kPa) & Youden Index & Sens. & Spec. & & & & & \\
\hline NASH acc. SAF $(n=154)$ & 0.640 & 6.0 & 0.270 & 53.6 & 46.4 & & & & & & NASH acc. SAF $n=170$ & 0.628 & 6.0 & 0.270 & 53.6 & 46.4 & & & & & \\
\hline $\mathrm{NASH}, \mathrm{BMI}<44.4 \mathrm{~kg} / \mathrm{m}^{2}(\mathrm{n}=82)$ & 0.547 & 6.0 & 0.270 & 80.6 & 46.4 & & & & & & $\mathrm{BMI}<44.4 \mathrm{~kg} / \mathrm{m}^{2}(\mathrm{n}=84)$ & 0.540 & 6.0 & 0.270 & 80.6 & 46.4 & & & & & \\
\hline $\mathrm{NASH}, \mathrm{BMI} \geq 44.4 \mathrm{~kg} / \mathrm{m}^{2}(\mathrm{n}=72)$ & 0.745 & 8.0 & 0.479 & 52.1 & 95.8 & & & & & & $\mathrm{BMI} \geq 44.4 \mathrm{~kg} / \mathrm{m}^{2}(\mathrm{n}=85)$ & 0.696 & 8.0 & 0.417 & 58.9 & 82.8 & & & & & \\
\hline CAPTM (PP) (NASH) & AUC & Cut off $(\mathrm{dB} / \mathrm{m})$ & Youden Index & Sens. & Spec. & & & & & & CAPTM (TD) (NASH) & AUC & Cut off $(\mathrm{dB} / \mathrm{m})$ & Youden Index & Sens. & Spec. & & & & & \\
\hline NASH acc. SAF $(n=134)$ & 0.758 & 323.5 & 0.423 & 80.3 & 62.1 & & & & & & NASH acc. SAF (n=148) & 0.758 & 323.5 & 0.415 & 81.2 & 60.3 & & & & & \\
\hline $\mathrm{NASH}, \mathrm{BMI}<44.4 \mathrm{~kg} / \mathrm{m}^{2}(\mathrm{n}=68)$ & 0.793 & 311.5 & 0.506 & 84.8 & 65.7 & & & & & & $\mathrm{BMI}<44.4 \mathrm{~kg} / \mathrm{m}^{2}(\mathrm{n}=70)$ & 0.786 & 311.5 & 0.492 & 85.3 & 63.9 & & & & & \\
\hline $\mathrm{NASH}, \mathrm{BMI} \geq 44.4 \mathrm{~kg} / \mathrm{m}^{2}(\mathrm{n}=68)$ & 0.719 & 369.5 & 0.381 & 51.2 & 87.0 & & & & & & $\mathrm{BMI} \geq 44.4 \mathrm{~kg} / \mathrm{m}^{2}(\mathrm{n}=78)$ & 0.727 & 369.0 & 0.420 & 56.9 & 85.2 & & & & & \\
\hline FAST (PP) (NASH) & AUC & Cut off & Youden Index & Sens. & Spec. & & & & & & FAST (ITD) (NASH) & AUC & Cut off & Youden Index & Sens. & Spec. & & & & & \\
\hline NASH acc. SAF ( $n=133)$ & 0.781 & 0.366 & 0.483 & 58.7 & 89.7 & & & & & & NASH acc. SAF (n=147) & 0.784 & 0.366 & 0.492 & 61.9 & 87.3 & & & & & \\
\hline $\mathrm{NASH}, \mathrm{BMI}<44.4 \mathrm{~kg} / \mathrm{m}^{2}(\mathrm{n}=68)$ & 0.787 & 0.128 & 0.509 & 90.9 & 60.0 & & & & & & $\mathrm{BMI}<44.4 \mathrm{~kg} / \mathrm{m}^{2}(\mathrm{n}=70)$ & 0.788 & 0.128 & 0.498 & 91.4 & 58.3 & & & & & \\
\hline $\mathrm{NASH}, \mathrm{BMI} \geq 44.4 \mathrm{~kg} / \mathrm{m}^{2}(\mathrm{n}=65)$ & 0.772 & 0.377 & 0.604 & 69.0 & 91.3 & & & & & & $\mathrm{BMI} \geq 44.4 \mathrm{~kg} / \mathrm{m}^{2}(\mathrm{n}=77)$ & 0.776 & 0.377 & 0.587 & 73.5 & 85.2 & & & & & \\
\hline FAST (PP) (active fibrotic NASH) & AUC & Cut off & Youden Index & Sens. & Spec. & & & & & & FAST (ITD) (active fibrotic NASH) & AUC & Cut off & Youden Index & Sens. & Spec. & & & & & \\
\hline Active fibrotic NASH (n=133) & 0.780 & 0.206 & 0.453 & 100.0 & 45.3 & & & & & & active fibrotic NASH (n=147) & 0.764 & 0.206 & 0.415 & 100.0 & 41.5 & & & & & \\
\hline $\mathrm{NASH}, \mathrm{BMI}<44.4 \mathrm{~kg} / \mathrm{m}^{2}(\mathrm{n}=68)$ & 0.836 & 0.261 & 0.661 & 100.0 & 66.1 & & & & & & $\mathrm{BMI}<44.4 \mathrm{~kg} / \mathrm{m}^{2}(\mathrm{n}=70)$ & 0.828 & 0.261 & 0.629 & 100.0 & 62.9 & & & & & \\
\hline $\mathrm{NASH}, \mathrm{BMI} \geq 44.4 \mathrm{~kg} / \mathrm{m}^{2}(\mathrm{n}=65)$ & 0.754 & 0.562 & 0.490 & 71.4 & 77.6 & & & & & & $\mathrm{BMI} \geq 44.4 \mathrm{~kg} / \mathrm{m}^{2}(\mathrm{n}=77)$ & 0.744 & 0.366 & 0.492 & 61.9 & 87.3 & & & & & \\
\hline
\end{tabular}

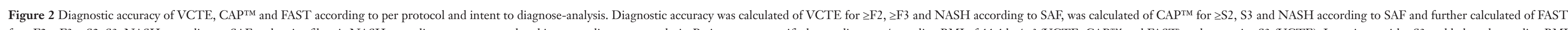

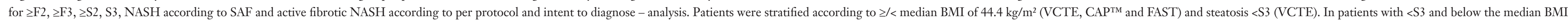

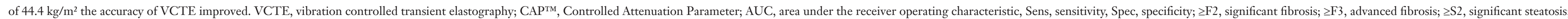
S3, severe steatosis; kPA, kilopascal; PP, per protocol; ITD, intent-to-diagnose; BMI, body mass index; NASH, non-alcoholic steatohepatitis; active fibrotic NASH, definition according to Newsome et al. (NASH + NAS $\geq 4+\mathrm{F} \geq 2$ ). 

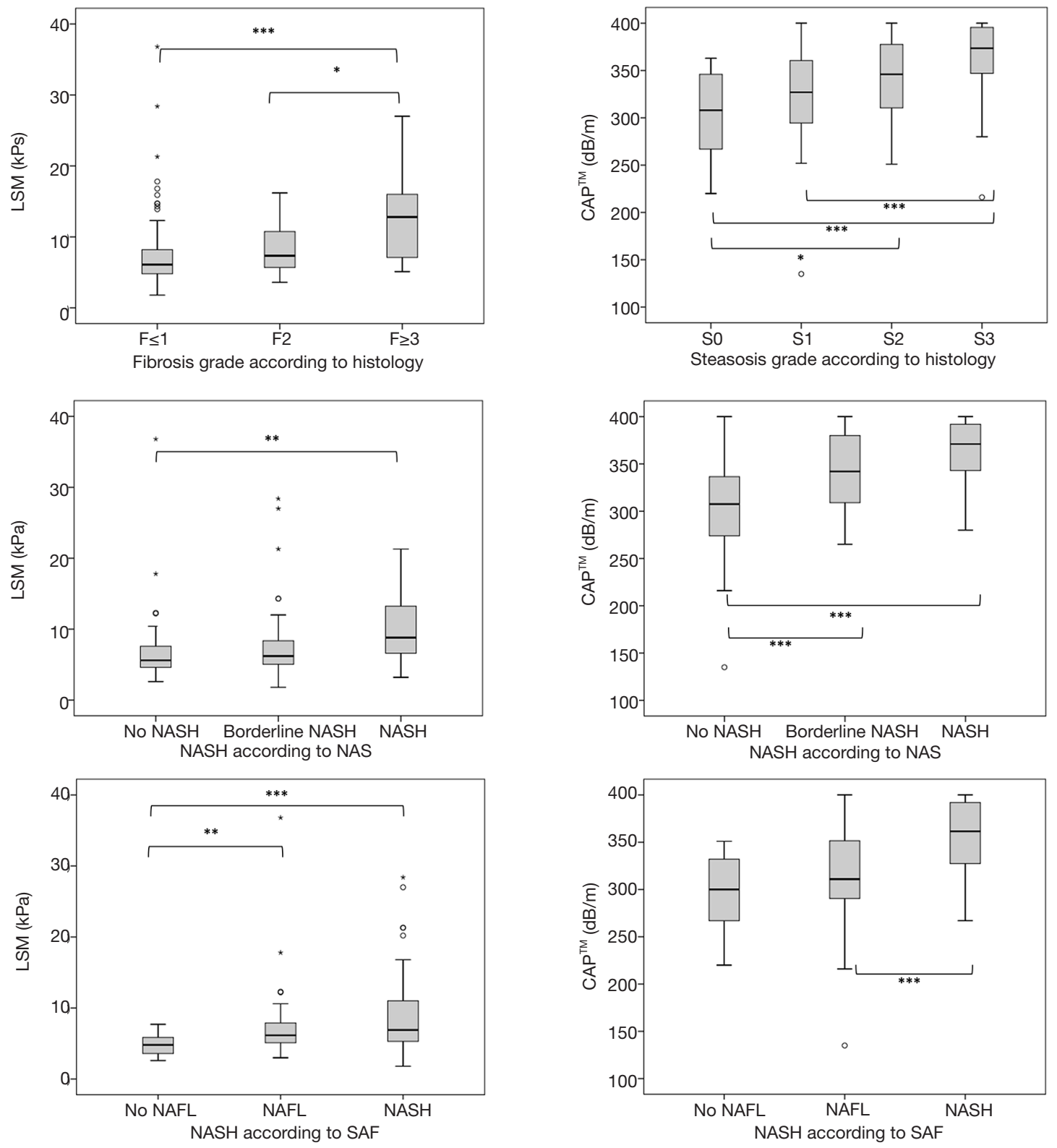

Figure 3 Per protocol liver stiffness measurement (LSM) and CAP ${ }^{\mathrm{TM}}$ distribution stratified for fibrosis, steatosis, and NASH according to histology. All groups were statistically compared, and significant differences marked by asterisks *, $\mathrm{P}<0.05 ;{ }^{* *}, \mathrm{P}<0.01 ;{ }^{* * *}, \mathrm{P}<0.001$. $\mathrm{F}$, fibrosis grade; S, steatosis grade; NAFL, non-alcoholic fatty liver; NASH, non-alcoholic steatohepatitis; SAF, Steatosis, Activity and Fibrosis score; NAS, NAFLD Activity Score; kPA, kilopascal; dB/m, decibel per meter.

\section{The influence of comorbidities on the diagnostic potential of VCTE and CAP TM}

To determine factors influencing VCTE and CAP ${ }^{\mathrm{TM}}$ univariate and multivariate linear regressions were calculated (Table S2). In the univariate analysis, BMI $(\mathrm{P}=0.008)$, macrovesicular $(\mathrm{P}=0.001)$ and total steatosis $(\mathrm{P}=0.008)$,
HbA1c ( $\mathrm{P}=0.042)$, GGT $(\mathrm{P}=0.036)$, HDL $(\mathrm{P}=0.026)$, and LDL $(\mathrm{P}=0.039)$ were independent confounders of LSM. BMI $(\mathrm{P}=0.004)$, fibrosis grade $(\mathrm{P}=0.023)$, HbA1c $(\mathrm{P}=0.011)$, HOMA-IR ( $\mathrm{P}=0.026)$, GGT ( $\mathrm{P}=0.035)$, HDL $(\mathrm{P}=0.008)$, and triglycerides $(\mathrm{P}=0.003)$ were influencing factors for $\mathrm{CAP}^{\mathrm{TM}}$. In multivariate linear regression there was a trend 
for $\mathrm{BMI}(\mathrm{P}=0.061)$ influencing $\mathrm{LSM}$ values. Concerning $\mathrm{CAP}^{\mathrm{TM}}$, BMI $(\mathrm{P}=0.005)$ and HbA1c $(\mathrm{P}=0.018)$ remained significant in the adjusted regression.

Comparing patients above and below the median BMI of $44.4 \mathrm{~kg} / \mathrm{m}^{2}$ (50.6\% vs. $49.4 \%$ ), there was no significant difference in $\geq \mathrm{F} 2$ (22.1\% vs. $21.4 \%, \mathrm{P}=0.916), \geq \mathrm{S} 2(44.2 \%$ vs. $40.5 \%, \mathrm{P}=0.625)$, NASH according to $\mathrm{SAF}(66.3 \%$ vs. $54.8 \%, \mathrm{P}=0.124)$ or active fibrotic NASH according to FAST score $(14.0 \%$ vs. $13.1 \%, \mathrm{P}=0.870)$. In contrast, patients with and without diabetes showed differences in significant fibrosis ( $\geq \mathrm{F} 245.8 \%$ vs. $12.3 \%, \mathrm{P}<0.001)$, significant steatosis $(54.2 \%$ vs. $37.7 \%, \mathrm{P}=0.051)$, NASH according to $\mathrm{SAF}(81.3 \%$ vs. $52.5 \%, \mathrm{P}=0.001)$ and active fibrotic NASH ( $31.3 \%$ vs. $6.6 \%, \mathrm{P}<0.001)$.

\section{Laboratory parameters}

Laboratory values assessed prior to the operation and three and 12 months thereafter are reported in Table S3 and Figure S1. Blood lipids (total cholesterol, triglycerides, LDL), as well as HbA1c $(\mathrm{P}<0.001)$ and HOMA-IR $(\mathrm{P}<0.001)$ significantly decreased 3 and 12 months after surgery, while HDL significantly increased 12 months after surgery $(\mathrm{P}<0.001)$. Median values of transaminases decreased after surgery, but this was only significant in GGT $(\mathrm{P}<0.001$ after 3 and 12 months). There was no significant difference in transaminases between patients with or without fibrosis as according to liver histology or LSM/CAP ${ }^{\mathrm{TM}}(\geq \mathrm{F} 2$ vs. $<\mathrm{F} 2$ or $\geq \mathrm{F} 3$ vs. $<\mathrm{F} 3$, data not shown) at the time of surgery. In patients with $\geq \mathrm{F} 2$, GGT significantly decreased over time. In contrast, in hepatic steatosis $(\geq \mathrm{S} 2 v s .<\mathrm{S} 2)$ significant differences in GGT were already present at the time of operation. However, independently of steatosis grade, GGT significantly decreased after surgery over time.

\section{Discussion}

We analysed the accuracy of VCTE, CAP ${ }^{\mathrm{TM}}$ and FAST score in a real life setting for their utility to non-invasively assess liver fibrosis, steatosis and NASH in patients with severe and morbid obesity undergoing bariatric-metabolic surgery. LSM by VCTE, CAPTM, and FAST achieved an acceptable accuracy (PP). However, in patients with a BMI $<44.4 \mathrm{~kg} / \mathrm{m}^{2}$ accuracy was improved.

The importance of non-invasive liver fibrosis detection and surveillance has continuously increased especially as obesity and concomitant NAFLD/NASH have reached considerate significance as a widespread disease. In our patient cohort the prevalence of biopsy proven NASH was $60.6 \%$, which is in line with previously published data on the prevalence of NASH in patients with obesity (27). However, to date, intraoperative liver biopsy has not been widely applied as a standard procedure during bariatric metabolic surgery, and non-invasive screening tools have not been independently validated for patients with severe to morbid obesity. Therefore, NASH and advanced fibrosis is at risk to be overlooked in bariatric-metabolic patients, but may lead to an increased intra- and perioperative risk (28).

Previously, increased failure rates of VCTE were reported to be associated with higher BMI (29). In a study with obese patients with a median BMI of $30 \mathrm{~kg} / \mathrm{m}^{2}$, the $\mathrm{XL}$-probe for LSM was superior compared to the M-probe, but reliable measurements were less likely in patients with a $\mathrm{BMI} \geq 40 \mathrm{~kg} / \mathrm{m}^{2}$ (16). Furthermore, studies that investigate exclusively patients with severe or morbid obesity (BMI $\geq 35.0 \mathrm{~kg} / \mathrm{m}^{2}$ ) are scarce, have high heterogeneity, small sample size and consider only few numbers of patients with significant to advanced fibrosis. In our study, the feasibility of LSM was $90.6 \%$ comparable to previously reported data (88.5-91.3\%) (30-32). Patients with unreliable VCTE results had a significantly higher BMI, and thus in the group above the median BMI of $44.4 \mathrm{~kg} / \mathrm{m}^{2}$ a higher percentage of unreliable results was found. In a study including 87 patients with a mean BMI of $51.6 \mathrm{~kg} / \mathrm{m}^{2}$ the feasibility of LSM was even only two thirds, and an association between increased subcutaneous fat and LSM failure was reported (33). However, in our study not only feasibility was significantly altered but also the diagnostic accuracy of VCTE was strongly affected especially in patients above the median BMI. In contrast, in patients with a BMI $<44.4 \mathrm{~kg} / \mathrm{m}^{2}$ we achieved an AUC of 0.842 for the diagnosis of advanced fibrosis, comparable to previously published results $(29,30)$.

When the XL-probe was first introduced, thresholds for fibrosis grading had to be modified as LSM by the XL-probe led to lower values, thereby underscoring fibrosis (17). Up to now, only a small amount of studies analysed patients with obesity and NAFLD, and report a wide cut off range between 7.6-12.5 $\mathrm{kPa}$ for the detection of advanced fibrosis $(29,30,34)$. Our findings are in line with previously published data (cut off for $\geq \mathrm{F} 3$ : $12.6 \mathrm{kPa}$ ). On the contrary, in patients with a BMI $\geq 44.4 \mathrm{~kg} / \mathrm{m}^{2}$ we found a considerably higher cut off of $14.1 \mathrm{kPa}$. Thus, for patients with severe to morbid obesity and NAFLD further studies are required to better define LSM cut off values or cut off ranges, respectively, for significant to advanced fibrosis (35-37). Too low cut off values in patients with obesity 
may further contribute to underestimation of liver fibrosis and low diagnostic accuracy of LSM (37). In our patients with morbid obesity, LSM levels increased significantly with progressive steatosis and NASH, and the predictive potential of VCTE was improved when patients with advanced steatosis were excluded. As previously reported, fatty liver itself may cause scattering artefacts and therefore lead to a reduced accuracy of LSM (15). This may be one of the causes for reduced diagnostic accuracy in patients with obesity as they have a higher degree of steatosis (38). For the detection of significant and severe steatosis CAP ${ }^{\mathrm{TM}}$ was a mediocre parameter achieving an AUC of 0.703 and 0.738 , respectively. Stratification for BMI moderately improved accuracy (AUC 0.712 and 0.780, respectively). In a study by Ooi et al. evaluating 82 patients prior to bariatric-metabolic surgery comparable diagnostic accuracy for significant steatosis (AUC 0.688), but inferior accuracy for severe steatosis (AUC 0.540) was reported (39).

After bariatric-metabolic surgery, steatosis and NASH resolve in the majority of cases (40). Nevertheless, accurate non-invasive NASH diagnosis has gained importance as NASH per se may become an indication for bariatric-metabolic surgery in the near future. Currently, a randomized controlled trial investigates the treatment of severe NASH with advanced liver fibrosis by bariatricmetabolic surgery in patients with mild obesity (41). In our study, we analysed the diagnostic accuracy of VCTE, CAP ${ }^{\mathrm{TM}}$ and FAST for the non-invasive detection of NASH. Whereas VCTE was not a useful parameter, $\mathrm{CAP}^{\mathrm{TM}}$ achieved an acceptable accuracy (AUC 0.758) similar to findings reported by Eddowes et al., investigating a patient cohort with a median BMI of $33.8 \mathrm{~kg} / \mathrm{m}^{2}$ (AUC of 0.710$)$ (12). Notably, accuracy for the detection of steatosis $(\geq \mathrm{S} 20.838, \mathrm{~S} 30.812)$ and NASH $(0.781)$ was improved when the composite score FAST comprising LSM, CAP ${ }^{\mathrm{TM}}$ and AST was used (19). FAST had a similar diagnostic performance for the outcome parameter of active fibrotic NASH as in the original publication's derivation cohort [0.780 (PP) vs. 0.800; median BMI $\left.34.2 \mathrm{~kg} / \mathrm{m}^{2}\right]$. The AUC for FAST substantially improved in patients with a BMI $<44.4 \mathrm{~kg} / \mathrm{m}^{2}$ (AUC 0.836). In contrast, in the French bariatric surgery cohort $(\mathrm{n}=110)$ of the above-mentioned study (median BMI $43.0 \mathrm{~kg} / \mathrm{m}^{2}$ ) FAST achieved an AUC of even 0.95 for active fibrotic NASH, which could not be reproduced in our cohort of 133 patients (PP analysis). As an explanation, this discrepancy could have occurred due to spectrum bias based on a lower prevalence of significant to advanced fibrosis, significant to severe steatosis, as well as comorbidities in the French cohort.

The laboratory parameters, AST and ALT were not useful to detect patients with significant to advanced fibrosis prior to surgery, but GGT was significantly higher in patient with significant steatosis. GGT significantly decreased after surgery. This may allude to the improvement of hepatic inflammation, fibrosis, and NASH as reported in a study by Dixon et al. that identified GGT as a predictor of histologic improvement as proven by follow up biopsies performed $29.5 \pm 10$ months after surgery (42). Unfortunately, a verification of this finding was not possible in our cohort, as consecutive follow up biopsies were not available.

A further limitation of our study was that the sample size was not sufficient to allow further stratifications for T2DM and the BMI classes "severe obesity", "morbid obesity" and "super obesity". Furthermore, an independent validation cohort would be required to confirm our results.

In conclusion, VCTE and CAP ${ }^{\mathrm{TM}}$ show acceptable accuracy for the detection of advanced fibrosis and significant to severe steatosis in patients with severe obesity. FAST was a good predictor of hepatic steatosis and active fibrotic NASH. Accuracy of VCTE, CAP ${ }^{\mathrm{TM}}$ and FAST improved in the cohort of patients below the median BMI of $44.4 \mathrm{~kg} / \mathrm{m}^{2}$. VCTE may be used as an additional tool for identifying patients at risk for advanced fibrosis, significant and severe steatosis and NASH, particularly when applied as the composite score of FAST.

\section{Acknowledgments}

Funding: None.

\section{Footnote}

Reporting Checklist: The authors have completed the STARD reporting checklist. Available at https://hbsn.amegroups. com/article/view/10.21037/hbsn-20-787/rc

Data Sharing Statement: Available at https://hbsn. amegroups.com/article/view/10.21037/hbsn-20-787/dss

Conflicts of Interest: All authors have completed the ICMJE uniform disclosure form (available at https://hbsn. amegroups.com/article/view/10.21037/hbsn-20-787/coif). Dr. MT reports personal fees from BMS, grants and personal fees from Falk Foundation, grants, personal fees and other from Gilead, grants, personal fees and other from Intercept, 
grants and personal fees from MSD, personal fees from Albireo, personal fees from Boehringer lngelheim, personal fees from BiomX, personal fees from Genfit, personal fees from Novartis, personal fees from Phenex, personal fees from Regulus, other from Abbvie, grants from Albireo, grants from Cymabay, grants from Takeda, outside the submitted work. In addition, Dr. MT has a patent Medical use of nor-UDCA (W02006119803 and W020099013334) licensed to Medical University of Graz. Dr. KS serves as an unpaid editorial board member of Hepatobiliary Surgery and Nutrition. The other authors have no conflicts of interest to declare.

Ethical Statement: The authors are accountable for all aspects of the work in ensuring that questions related to the accuracy or integrity of any part of the work are appropriately investigated and resolved. The study was conducted in accordance with the Declaration of Helsinki (as revised in 2013). The study was approved by institutional ethics board of the Medical University of Vienna (vote number 2297/2017) and individual consent for this retrospective analysis was waived.

Open Access Statement: This is an Open Access article distributed in accordance with the Creative Commons Attribution-NonCommercial-NoDerivs 4.0 International License (CC BY-NC-ND 4.0), which permits the noncommercial replication and distribution of the article with the strict proviso that no changes or edits are made and the original work is properly cited (including links to both the formal publication through the relevant DOI and the license). See: https://creativecommons.org/licenses/by-nc-nd/4.0/.

\section{References}

1. Clark JM. The epidemiology of nonalcoholic fatty liver disease in adults. J Clin Gastroenterol 2006;40 Suppl 1:S5-10.

2. Bedossa P, Tordjman J, Aron-Wisnewsky J, et al. Systematic review of bariatric surgery liver biopsies clarifies the natural history of liver disease in patients with severe obesity. Gut 2017;66:1688-96.

3. Sasaki A, Nitta H, Otsuka K, et al. Bariatric surgery and non-alcoholic Fatty liver disease: current and potential future treatments. Front Endocrinol (Lausanne) 2014;5:164.

4. Diehl AM, Day C. Cause, Pathogenesis, and Treatment of Nonalcoholic Steatohepatitis. N Engl J Med 2017;377:2063-72.

5. Kral JG, Thung SN, Biron S, et al. Effects of surgical treatment of the metabolic syndrome on liver fibrosis and cirrhosis. Surgery 2004;135:48-58.

6. Younossi ZM, Loomba R, Rinella ME, et al. Current and future therapeutic regimens for nonalcoholic fatty liver disease and nonalcoholic steatohepatitis. Hepatology 2018;68:361-71.

7. Klebanoff MJ, Corey KE, Chhatwal J, et al. Bariatric surgery for nonalcoholic steatohepatitis: A clinical and cost-effectiveness analysis. Hepatology 2017;65:1156-64.

8. Mosko JD, Nguyen GC. Increased perioperative mortality following bariatric surgery among patients with cirrhosis. Clin Gastroenterol Hepatol 2011;9:897-901.

9. Staufer K, Halilbasic E, Spindelboeck W, et al. Evaluation and comparison of six noninvasive tests for prediction of significant or advanced fibrosis in nonalcoholic fatty liver disease. United European Gastroenterol J 2019;7:1113-23.

10. European Association for Study of Liver; Asociacion Latinoamericana para el Estudio del Higado. EASLALEH Clinical Practice Guidelines: Non-invasive tests for evaluation of liver disease severity and prognosis. J Hepatol 2015;63:237-64.

11. Karlas T, Petroff D, Sasso M, et al. Individual patient data meta-analysis of controlled attenuation parameter (CAP) technology for assessing steatosis. J Hepatol 2017;66:1022-30.

12. Eddowes PJ, Sasso M, Allison M, et al. Accuracy of FibroScan Controlled Attenuation Parameter and Liver Stiffness Measurement in Assessing Steatosis and Fibrosis in Patients With Nonalcoholic Fatty Liver Disease. Gastroenterology 2019;156:1717-30.

13. Castera L, Foucher J, Bernard PH, et al. Pitfalls of liver stiffness measurement: a 5-year prospective study of 13,369 examinations. Hepatology 2010;51:828-35.

14. Wong VW, Vergniol J, Wong GL, et al. Diagnosis of fibrosis and cirrhosis using liver stiffness measurement in nonalcoholic fatty liver disease. Hepatology 2010;51:454-62.

15. Durango E, Dietrich C, Seitz HK, et al. Direct comparison of the FibroScan XL and M probes for assessment of liver fibrosis in obese and nonobese patients. Hepat Med 2013;5:43-52.

16. Myers RP, Pomier-Layrargues G, Kirsch R, et al. Feasibility and diagnostic performance of the 
FibroScan XL probe for liver stiffness measurement in overweight and obese patients. Hepatology 2012;55:199-208.

17. Wong VW, Vergniol J, Wong GL, et al. Liver stiffness measurement using XL probe in patients with nonalcoholic fatty liver disease. Am J Gastroenterol 2012;107:1862-71.

18. de Ledinghen V, Vergniol J, Foucher J, et al. Feasibility of liver transient elastography with FibroScan using a new probe for obese patients. Liver Int 2010;30:1043-8.

19. Newsome PN, Sasso M, Deeks JJ, et al. FibroScanAST (FAST) score for the non-invasive identification of patients with non-alcoholic steatohepatitis with significant activity and fibrosis: a prospective derivation and global validation study. Lancet Gastroenterol Hepatol 2020;5:362-73.

20. Fried M, Yumuk V, Oppert JM, et al. Interdisciplinary European Guidelines on metabolic and bariatric surgery. Obes Facts 2013;6:449-68.

21. IDF Consensus Worldwide Definition of the Metabolic Syndrome. 2006.

22. European Association for the Study of the Liver (EASL); European Association for the Study of Diabetes (EASD); European Association for the Study of Obesity (EASO). EASL-EASD-EASO Clinical Practice Guidelines for the management of non-alcoholic fatty liver disease. J Hepatol 2016;64:1388-402.

23. Boursier J, de Ledinghen V, Poynard T, et al. An extension of STARD statements for reporting diagnostic accuracy studies on liver fibrosis tests: the Liver-FibroSTARD standards. J Hepatol 2015;62:807-15.

24. Kleiner DE, Brunt EM, Van Natta $M$, et al. Design and validation of a histological scoring system for nonalcoholic fatty liver disease. Hepatology 2005;41:1313-21.

25. Bedossa P, Poitou C, Veyrie N, et al. Histopathological algorithm and scoring system for evaluation of liver lesions in morbidly obese patients. Hepatology 2012;56:1751-9.

26. Youden WJ. Index for rating diagnostic tests. Cancer 1950;3:32-5.

27. Younossi Z, Anstee QM, Marietti M, et al. Global burden of NAFLD and NASH: trends, predictions, risk factors and prevention. Nat Rev Gastroenterol Hepatol 2018;15:11-20.

28. Mahawar KK, Parmar C, Graham Y, et al. Routine Liver Biopsy During Bariatric Surgery: an Analysis of Evidence Base. Obesity Surgery 2016;26:177-81.

29. Naveau S, Lamouri K, Pourcher G, et al. The diagnostic accuracy of transient elastography for the diagnosis of liver fibrosis in bariatric surgery candidates with suspected NAFLD. Obes Surg 2014;24:1693-701.

30. Garg H, Aggarwal S, Shalimar, et al. Utility of transient elastography (fibroscan) and impact of bariatric surgery on nonalcoholic fatty liver disease (NAFLD) in morbidly obese patients. Surg Obes Relat Dis 2018;14:81-91.

31. Patel P, Hossain F, Horsfall LU, et al. A Pragmatic Approach Identifies a High Rate of Nonalcoholic Fatty Liver Disease With Advanced Fibrosis in Diabetes Clinics and At-Risk Populations in Primary Care. Hepatol Commun 2018;2:893-905.

32. Chen J, Yin M, Talwalkar JA, et al. Diagnostic Performance of MR Elastography and Vibration-controlled Transient Elastography in the Detection of Hepatic Fibrosis in Patients with Severe to Morbid Obesity. Radiology 2017;283:418-28.

33. Weiss J, Rau M, Meertens J, et al. Feasibility of liver stiffness measurement in morbidly obese patients undergoing bariatric surgery using XL probe. Scand J Gastroenterol 2016;51:1263-8.

34. Ooi GJ, Mgaieth S, Eslick GD, et al. Systematic review and meta-analysis: non-invasive detection of non-alcoholic fatty liver disease related fibrosis in the obese. Obes Rev 2018;19:281-94.

35. Lim JK, Flamm SL, Singh S, et al. American Gastroenterological Association Institute Guideline on the Role of Elastography in the Evaluation of Liver Fibrosis. Gastroenterology 2017;152:1536-43.

36. Mikolasevic I, Orlic L, Franjic N, et al. Transient elastography (FibroScan $(\circledR)$ ) with controlled attenuation parameter in the assessment of liver steatosis and fibrosis in patients with nonalcoholic fatty liver disease - Where do we stand? World J Gastroenterol 2016;22:7236-51.

37. Karlas T, Dietrich A, Peter V, et al. Evaluation of Transient Elastography, Acoustic Radiation Force Impulse Imaging (ARFI), and Enhanced Liver Function (ELF) Score for Detection of Fibrosis in Morbidly Obese Patients. PLoS One 2015;10:e0141649.

38. Hagstrom H, Nasr P, Ekstedt M, et al. Risk for development of severe liver disease in lean patients with nonalcoholic fatty liver disease: A long-term follow-up study. Hepatol Commun 2018;2:48-57.

39. Ooi GJ, Earnest A, Kemp WW, et al. Evaluating feasibility and accuracy of non-invasive tests for nonalcoholic fatty liver disease in severe and morbid obesity. Int J Obes (Lond) 2018;42:1900-11. 
40. Luo RB, Suzuki T, Hooker JC, et al. How bariatric surgery affects liver volume and fat density in NAFLD patients. Surg Endosc 2018;32:1675-82.

41. A Randomized Controlled Study Evaluating Bariatric Surgery as a Treatment for Severe NASH With Advanced Liver Fibrosis in Non-severe Obese Patients

Cite this article as: Eilenberg M, Munda P, Stift J, Langer FB, Prager G, Trauner M, Staufer K. Accuracy of non-invasive liver stiffness measurement and steatosis quantification in patients with severe and morbid obesity. HepatoBiliary Surg Nutr 2021;10(5):610-622. doi: 10.21037/hbsn-20-787
(NASHSURG) [database on the Internet] 2018. Available online: https://clinicaltrials.gov/ct2/show/NCT03472157

42. Dixon JB, Bhathal PS, O'Brien PE. Weight loss and nonalcoholic fatty liver disease: falls in gamma-glutamyl transferase concentrations are associated with histologic improvement. Obes Surg 2006;16:1278-86. 


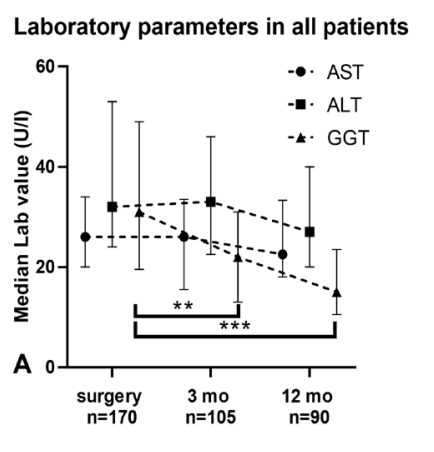

Laboratory parameters in patients $\geq F$ 2 (histology)

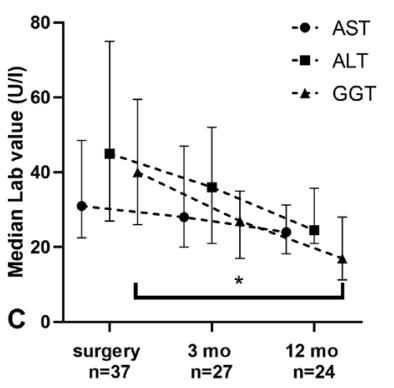

Laboratory parameters in patients $\geq \mathbf{S} 2$ (histology)

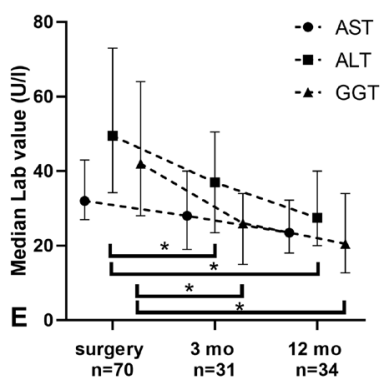

GGT in patients $\leq \mathbf{S} 2$ vs. $\geq \mathbf{S} 2$ (histology)

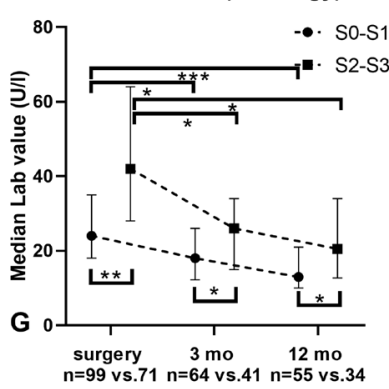

Laboratory parameters in patients with NASH (SAF)

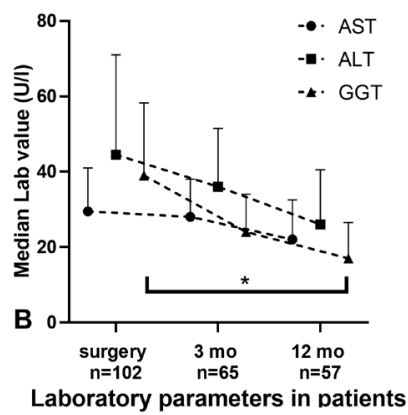

$\geq$ F2 (LSM)

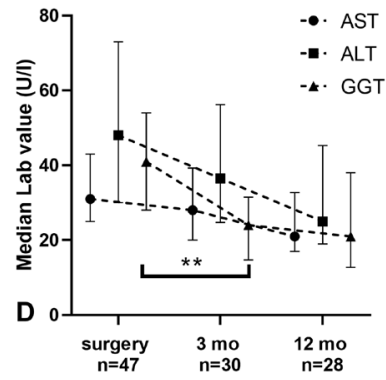

Laboratory parameters in patients $\geq$ S2 (CAP)

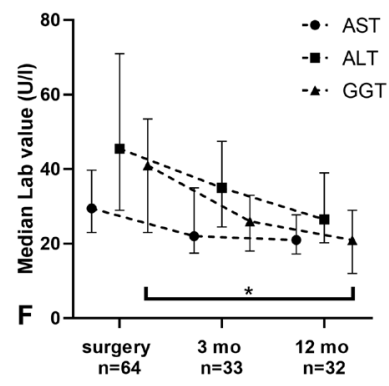

GGT in patients

$\leq S 2$ vs. $\geq$ S2 (CAP)

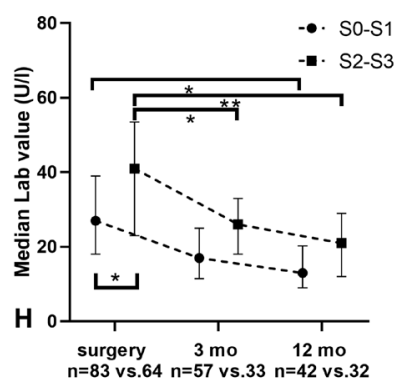

Figure S1 Evolution of laboratory values in NASH, significant fibrosis $\geq \mathrm{F} 2$ and steatosis $\geq \mathrm{S} 2$ according to histology, LSM and CAP ${ }^{\mathrm{TM}}$. All groups were statistically compared, and significant differences marked by asterisks *, $\mathrm{P}<0.05 ;{ }^{* *}, \mathrm{P}<0.01 ;{ }^{* * *}, \mathrm{P}<0.001$. GGT was significantly decreased over time, in NASH patients, significant fibrosis and steatosis. Laboratory courses were similar in stratifications according to histology versus LSM or CAP ${ }^{\text {TM }}$. CAP ${ }^{\mathrm{TM}}$ for steatosis grades $\geq \mathrm{S} 2$ was calculated by determination of a cutoff (350.0 d/m) by Youden Index. The cutoff ( $8.3 \mathrm{kPA})$ for $\geq \mathrm{F} 2$ was calculated by Youden Index as for patients with a BMI $<44.4 \mathrm{~kg} / \mathrm{m}^{2}$ due the higher sensitivity and specificity. AST, aspartate aminotransferase; ALT, alanine aminotransferase; GGT, gamma-glutamyl transferase; S, steatosis grade; NASH, Non-alcoholic steatohepatitis, SAF, Steatosis, Activity and Fibrosis score. 
Table S1 LSM and CAP ${ }^{\mathrm{TM}}$ results stratified according to histopathology

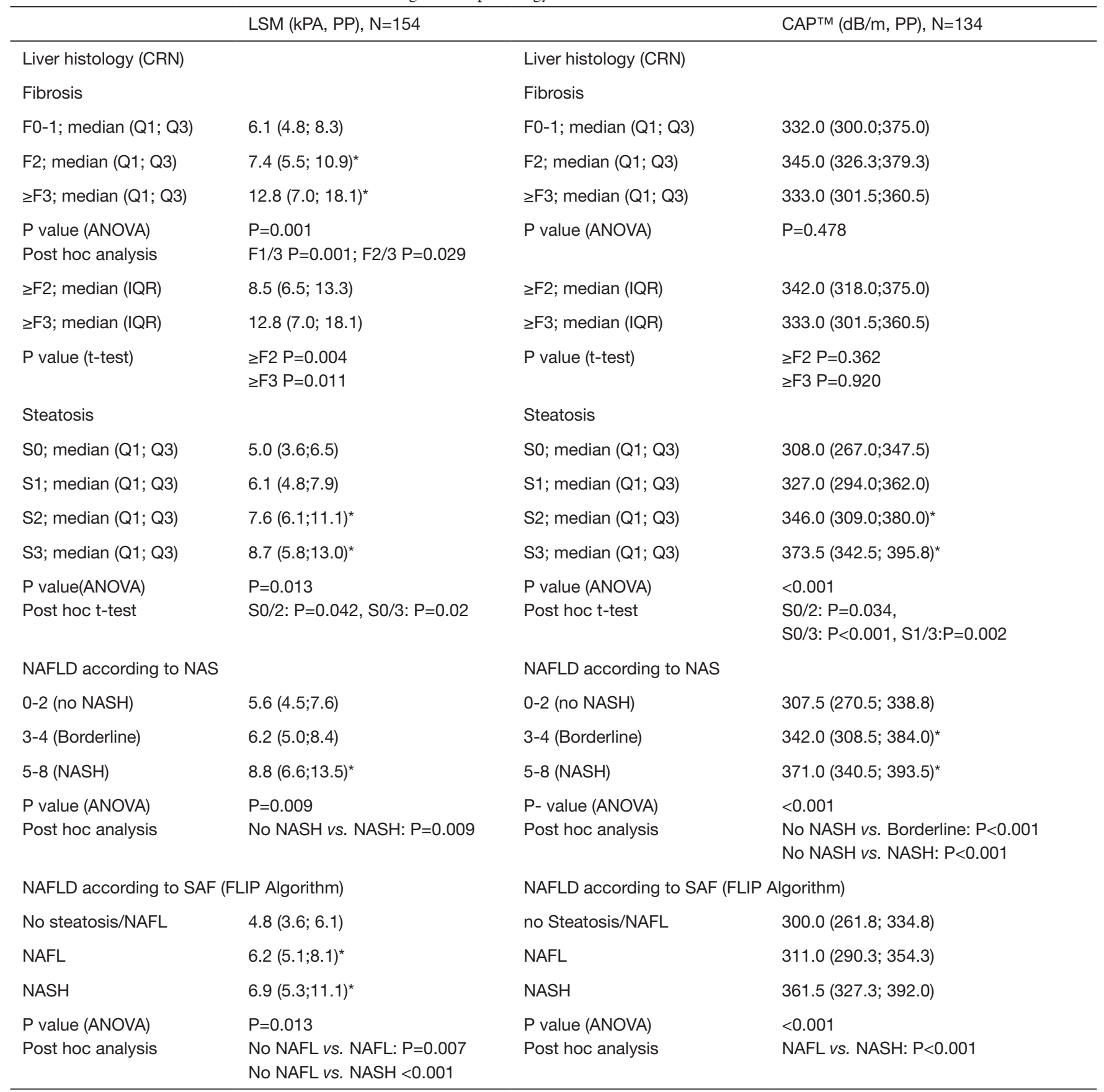

VCTE values increased with higher fibrosis, but also with higher steatosis grades according to CRN. LSM was increased with higher NAS (NASH) and SAF (NAFLD, NASH) (per protocol analysis). CAPTM values increased with higher steatosis grades according to CRN, with NAS (NASH and borderline NASH) and SAF (NASH) (per protocol analysis. * indicates significant differences in relation to baseline. SAF, Steatosis, Activity and Fibrosis score; NAS, NAFLD Activity Score; NAFL, Non-alcoholic fatty liver; NASH, Non-alcoholic steatohepatitis; CAP'M, Controlled Attenuation Parameter; kPA, kilopascal. 
Table S2 Factors influencing liver stiffness measurement (LSM) and controlled attenuation parameter (CAP) assessed by multivariate linear regression analysis

\begin{tabular}{|c|c|c|c|c|c|c|c|c|c|}
\hline & LSM & & & & & CAP & & & \\
\hline & $\begin{array}{l}\text { Unadjusted regression } \\
\text { coefficient }(95 \% \mathrm{Cl})\end{array}$ & $P$ value & $\begin{array}{l}\text { Adjusted regression } \\
\text { coefficient }(95 \% \mathrm{Cl})\end{array}$ & $P$ value & & $\begin{array}{l}\text { Unadjusted regression } \\
\text { coefficient }(95 \% \mathrm{Cl})\end{array}$ & $\begin{array}{l}\mathrm{P} \\
\text { value }\end{array}$ & $\begin{array}{l}\text { Adjusted regression } \\
\text { coefficient }(95 \% \mathrm{Cl})\end{array}$ & $P$ value \\
\hline BMI & $0.212(0.046 ; 0.307)$ & 0.008 & $0.115(-0.005 ; 0.236)$ & 0.061 & $\mathrm{BMI}$ & $0.250(0.676 ; 3.368$ & 0.004 & $1.749(0.542 ; 2.956)$ & 0.005 \\
\hline Steatosis (total) & $0.214(0.009 ; 0.059)$ & 0.008 & $0.023(-0.027 ; 0.073)$ & 0.112 & Fibrosis & $0.196(1.504 ; 20.379)$ & 0.023 & & \\
\hline $\begin{array}{l}\text { Macrovesicular } \\
\text { steatosis }\end{array}$ & $0.292(0.02 ; 0.73)$ & 0.001 & $0.02(-0.035 ; 0.075)$ & 0.750 & $\mathrm{HbA1c}$ & $0.236(1.92 ; 14.615)$ & 0.011 & $8.128(1.442 ; 14.814)$ & 0.018 \\
\hline $\mathrm{HbA1c}$ & $0.175(0.027 ; 1.480)$ & 0.042 & & & HOMA-IR & $0.210(0.116 ; 1.758)$ & 0.026 & & \\
\hline GGT & $0.170(0.001 ; 0.037)$ & 0.036 & & & GGT & $0.183(0.014 ; 370)$ & 0.035 & & \\
\hline HDL & $0.190(-128 ;-0.008)$ & 0.026 & & & HDL & $0.243(-1.342 ;-0.207)$ & 0.008 & $-0.528(-1.138 ; 0.082)$ & 0.089 \\
\hline LDL & $0.180(-0.055 ;-0.001)$ & 0.039 & & & $\mathrm{TG}$ & $0.262(0.052 ; 0.241)$ & 0.003 & $0.025(-0.071 ; 0.12)$ & 0.609 \\
\hline
\end{tabular}

Following parameters were analyzed by the univariate linear regression analysis: platelets, aspartate aminotransferase; alanine aminotransferase; gamma-glutamyl transferase (GGT); High-density lipoprotein (HDL); Low-density lipoprotein (LDL); glycosylated hemoglobin (HbA1c); Homeostatic Model Assessment for Insulin Resistance (HOMA-IR), ferritin, albumin, total cholesterol, triglycerides (TG), fibrosis grade (for CAPTM); total, microvesicular and macrovesicular steatosis (for LSM), patients' age and body mass index (BMI). Only significant values from the regression are listed. Adjusted regression coefficient was then assessed for all parameters with a significance level of $\mathrm{P}<0.02$. All $\mathrm{P}$ values are given for parameters that were included in the multivariate linear regression. Statistical significance was reached at $\mathrm{P} \leq 0.05$. $\mathrm{Cl}$, confidence interval.

Table S3 Changes of laboratory parameters over time

\begin{tabular}{|c|c|c|c|c|c|}
\hline Laboratory parameters & Prior to surgery $(\mathrm{N}=170)$ & $\begin{array}{l}3 \text { months post-surgery } \\
\qquad(\mathrm{N}=106)\end{array}$ & $\begin{array}{l}\text { P value baseline } \\
\text { vs. } 3 \text { months }\end{array}$ & $\begin{array}{l}12 \text { months post-surgery } \\
\qquad \mathrm{N}=91\end{array}$ & $\begin{array}{l}\text { P value baseline vs. } \\
12 \text { months }\end{array}$ \\
\hline Platelets (G/L), median (Q1; Q3) & $269.5(225.8 ; 319.0)$ & $250.5(217.5 ; 293.0)$ & 0.017 & $252.0(212.0 ; 282.0)$ & 0.003 \\
\hline AST (U/L), median (Q1; Q3) & $26.0(20.0 ; 34.0)$ & $26.0(18.5 ; 33.5)$ & 0.541 & $22.5(18.0 ; 33.3)$ & 0.631 \\
\hline ALT (U/L), median (Q1; Q3) & $32.0(24.0 ; 53.0)$ & $33.0(22.5 ; 46.0)$ & 0.508 & $27.0(20.0 ; 40.0)$ & 0.211 \\
\hline GGT (U/L), median (Q1; Q3) & $31(19.5 ; 49.0)$ & $22.0(13.0 ; 31.0)$ & $<0.001$ & $15.0(10.5 ; 23.5)$ & $<0.001$ \\
\hline Ferritin (ng/mL), median (Q1; Q3) & $86.4(48.0 ; 167.0)$ & $110.6(53.9 ; 147.0)$ & 0.742 & $77.1(29.1 ; 126.0)$ & 0.055 \\
\hline Albumin (g/L), median (Q1; Q3) & $42.4(40.4 ; 44.5)$ & $42.4(40.5 ; 44.8)$ & 0.344 & $42.3(39.6 ; 44.1)$ & 0.061 \\
\hline Total cholesterol (mg/dl), median (Q1; Q3) & $177.5(150.8 ; 200.5)$ & $156.5(137.0 ; 178.0)$ & $<0.001$ & $154.0(139.3 ; 171.0)$ & $<0.001$ \\
\hline HDL (mg/dL), median (Q1; Q3) & $42.0(35.0 ; 50.0)$ & $40.0(34.0 ; 48.0)$ & 0.045 & $52.5(45.0 ; 61.5)$ & $<0.001$ \\
\hline LDL (mg/dL), median (Q1; Q3) & $111.8(87.7 ; 129.8)$ & $89.6(74.6 ; 106.8)$ & $<0.001$ & $81.9(69.4 ; 102.6)$ & $<0.001$ \\
\hline Triglycerides (mg/dL), median (Q1; Q3) & $132(100.5 ; 195.0)$ & $110.0(86.0 ; 143.5 .0)$ & $<0.001$ & $85.0(67.0 ; 111.5)$ & $<0.001$ \\
\hline HbA1c (\%), median (Q1; Q3) & $5.6(5.4 ; 6.4)$ & $5.2(4.9 ; 5.5)$ & $<0.001$ & $5.0(4.8 ; 5.3)$ & $<0.001$ \\
\hline $\mathrm{HbA} 1 \mathrm{c}>6.5 \%, \%(\mathrm{n})$ & $20.9(31 / 148)$ & $2.0(2 / 100)$ & $<0.001$ & $1.23(1 / 81)$ & $<0.001$ \\
\hline HOMA-IR, median (Q1; Q3) & $6.0(3.7 ; 12.1)$ & $2.3(1.4 ; 3.6)$ & $<0.001$ & $1.5(1.0 ; 2.3)$ & $<0.001$ \\
\hline HOMA-IR > 2.5, \% (n) & $87.6(129 / 146)$ & $47.9(45 / 94)$ & $<0.001$ & $21.1(16 / 76)$ & $<0.001$ \\
\hline
\end{tabular}

Statistical differences between preoperatively at the day of surgery were compared to 3 and 12 months postoperatively, respectively (T- Test for parametric, Mann-Whitney U - Test for non-parametric data). In our study we were able to reproduce previously reported postoperative improvement of blood lipids, glucose homeostasis and GGT as typical for patients after bariatric-metabolic surgery (43-45). The transaminases AST and ALT did not significantly decrease three and 12 months after bariatric surgery in contrast to the Swedish Obese Subjects (SOS) Study (45). GGT was significantly reduced over time as in line with the study by Dixon et al that identified GGT as a predictor of histologic improvement (42). VCTE, Vibration controlled transient elastography; AST, aspartate aminotransferase; ALT, alanine aminotransferase; GGT, gamma-glutamyl transferase; HDL, High-density lipoprotein; LDL, Low-density lipoprotein; HbA1c, glycosylated hemoglobin; HOMA-IR, Homeostatic Model Assessment for Insulin Resistance. 


\section{References}

43. Johansson HE, Wåhlén A, Aldenbäck E, et al. Platelet Counts and Liver Enzymes After Gastric Bypass Surgery. Obes Surg 2018;28:1526-31.

44. Fraszczyk E, Luijten M, Spijkerman AMW, et al. The effects of bariatric surgery on clinical profile, DNA methylation, and ageing in severely obese patients. Clin Epigenetics 2020;12:14.

45. Burza MA, Romeo S, Kotronen A, Svensson PA, Sjöholm K, Torgerson JS, Lindroos AK, Sjöström L, Carlsson LM, Peltonen M. Long-term effect of bariatric surgery on liver enzymes in the Swedish Obese Subjects (SOS) study. PLoS One 2013;8:e60495. 